\title{
Upaya Pengelola Dalam Peningkatan Minat Baca Masyarakat Di Taman Bacaan Masyarakat Cellpower Indonesia
}

\author{
Anifah $^{\mathbf{1}^{*}}$, Boy Manalu ${ }^{2}$ \\ ${ }^{1}$ Pendidikan Masyarakat, Universitas Negeri Medan \\ ${ }^{2}$ Dinas Pendidikan, Kota Pematang Siantar \\ *Korespondensi Penulis. Email: anifahpilchan@unimed.ac.id
}

\begin{abstract}
Abstrak
Penelitian bertujuan untuk mengetahui serta mendeskripsikan upaya pengelola dalam peningkatan minat baca masyarakat di TBM CellPower Indonesia Kec. Medan Polonia Kota Medan. Jenis penelitian ini adalah deskriptif kualitatif, informan yaitu pengelola 1 orang, tutor 1 orang dan 2 orang pengunjung TBM CellPower Indonesia. Data dikumpulkan dengan teknik wawancara dan dokumentasi, dan dianalisis dengan langkah: pengumpulan data, reduksi data, display data, dan menarik kesimpulan. Hasil penelitian ini menunjukkan bahwa pengelola yang berada di TBM CellPower Indonesia Kota Medan, dalam menumbuhkan minat baca masyarakat yang berkunjung ke TBM CellPower Indonesia melakukan tindakan seperti, menyediakan buku-buku ataupun bahan bacaan yang lengkap bagi para pengunjung mulai dari bahan bacaan yang berbau pendidikan, pengetahuan umum, kesehatan, serta surat kabar. Menyediakan tempat membaca/ ruang baca yang aman dan nyaman, menambah kegiatan/program tambahan untuk menambah daya tarik pengunjung untuk membaca berupa lomba baca buku, bazar, pentas seni musik, bulan berbagi buku, memberikan informasi kepada pengunjung ataupun masyarakat serta menambah waktu berkunjung.
\end{abstract}

Kata Kunci : Upaya Pengelola,Minat Baca Masyarakat

\begin{abstract}
The research aims to find out and describe the efforts of managers in increasing public reading interest in TBM CellPower Indonesia Kec. Medan Polonia Medan City. This type of research is descriptive qualitative, informants, namely managers of 1 person, tutors 1 person and 2 people visitors to TBM CellPower Indonesia. Data is collected by interview techniques and documentation, and analyzed by steps: data collection, data reduction, data display, and drawing conclusions. The results of this study indicate that managers who are in TBM CellPower Indonesia Medan City, in growing reading interest of the people who visit TBM CellPower Indonesia take actions such as providing complete books or reading material for visitors ranging from reading materials that are educational in nature. general knowledge, health, and newspapers. Providing a safe and comfortable reading / reading room, adding additional activities / programs to add to the attractiveness of visitors to read in the form of reading books, bazaars, musical performances, months of sharing books, providing information to visitors or the public and increasing visiting time.
\end{abstract}

Keywords: Management Efforts, Public Reading Interest 


\section{PENDAHULUAN}

Sebagai salah satu program pendidikan non formal dan dalam rangka ikut mencerdaskan kehidupan anak bangsa serta usaha melestarikan program pendidikan non formal melalui salah satu program pemberdayaan masyarakat dengan pengembangan gerakan literasi serta pengembangan budaya baca pada masyarakat akan meningkatkan pengetahuan dan wawasan yang lebih baik dan berarah pada progress atas kehidupan serta berkepribadian baik secara pribadi, kelompok maupun dalam bermasyarakat.

Hal ini merupakan tanggung jawab negara baik itu dari pusat maupun pada tingkatan daerah dan semua komponen bangsa untuk memenuhinya, apalagi dikaitkan dengan amanat konstitusi kita yang menyatakan bahwa negara berkewajiban untuk "mencerdaskan kehidupan anak bangsa" yang secara spesifik memiliki kewajiban untuk meningkatkan minat baca masyarakat yang diatur dalam Undang-undang Nomor 43 Tahun 2007 tentang Perpustakaan (UU Perpustakaan). Yang mana dinyatakan bahwa, pemerintah berkewajiban untuk mengembangkan sistem nasional perpustakaan sebagai upaya mendukung sistem pendidikan nasional, menjamin kelangsungan penyelenggaraan dan pengelolaan perpustakaan sebagai pusat sumber belajar masyarakat, menjamin ketersediaan layanan perpustakaan secara merata di tanah air. Selanjutnya dijelaskan pada Pasal 48 sampai dengan Pasal 51 UU Perpustakaan yang mengatur pada pembudayaan kegemaran membaca. Pembudayaan tersebut dilakukan melalui keluarga, satuan pendidikan, dan masyarakat, yang difasilitasi oleh pemerintah pusat dan pemerintah daerah melalui buku murah dan berkualitas. Pemerintah pusat, pemerintah daerah, dan masyarakat mendorong tumbuhnya taman bacaan masyarakat dan rumah baca demi menunjang pembudayaan kegemaran membaca (Pasal 49).

Sampai dengan era globalisasi saat ini yang sangat erat kaitannya dengan modernisasi dan selalu membutuhkan teknologi dan informasi dalam pelaksanaannya serta dapat diartikan juga sebagai jaman persaingan bebas baik dari segi perekonomian, pertahanan nasional, perkembangan teknologi dan sebagainya. Page |37 Bangsa Indonesia dalam hal ini mau tidak mau dituntut untuk selalu meningkatkan perkembangan teknologi dan informasi serta wawasan luas dari segala aspek tanpa meninggalkan adat ketimuran yang selalu dianut oleh Bangsa Indonesia sejak jaman sebelum kemerdekaan sampai dengan zaman sekarang ini. Sebagai salah satu dari implementasi program pemerintah yang turut mendukung pembangunan dunia pendidikan adalah dengan peningkatan minat baca dan pengembangan model Taman Bacaan Masyarakat (TBM) serta gerakan literasi. Pengembangan program pendidikan berupa program Pengembangan Taman Bacaan Masyarakat (TBM) adalah salah satu program pemerintah yang mengacu juga pada Undang-Undang Negara Republik Indonesia Nomor 20 tahun 2003 tentang Sistem Pendidikan Nasional, pasal 26 ayat (4), yang tercantum bahwa satuan pendidikan non formal terdiri atas lembaga kursus, lembaga pelatihan, kelompok belajar, pusat kegiatan belajar masyarakat, majelis taklim, serta satuan pendidikan yang sejenis.

Berbagai fakta menunjukkan bahwa budaya baca masyarakat di Indonesia sampai dengan sekarang ini sangatlah rendah, dikarenakan rendahnya minat baca di Indonesia dilihat dari beberapa buktibukti maupun riset yang sudah dilakukan. Berdasarkan Badan Pusat Statistik (BPS) mencatat bahwa hanya sekitar 17,66 persen yang menyukai membaca surat kabar, buku atau majalah. Konsumsi satu surat kabar di Indonesia dengan pembacanya mempunyai rasio satu berbanding 45 orang (1:45). Rasio tersebut sangat jauh dibanding negara ASEAN lainya seperti Filipina yang perbandingannya mencapai (1:30). Kondisi saat ini tercatat bahwa satu buku dibaca sekitar 80.000 penduduk Indonesia. pada tahun 2011 tercatat produksi buku di Indonesia sekitar 20.000 judul buku. Jika 
dibandingkan dengan penduduk Indonesia yang sekitar 240 juta, angka ini sangat memiriskan.

Rendahnya minat baca juga disebabkan membaca perlu banyak waktu luang, Sementara orang Indonesia waktunya lebih banyak tersita untuk bekerja demi mempertahankan hidup dan meningkatkan kesejahteraan. Harga buku juga ikut andil menjadi pemicu rendahnya tingkat membaca. Pemerintah dalam hal ini kementrian pendidikan nasional menyatakan bahwa gerakan literasi dan budaya membaca yang menjangkau masyarakat dapat di percepat dan di tingkatkan melalui program pemerintah yakni salah satunya dengan taman bacaan masyarakat ( TBM ). Taman Bacaan Masyarakat merupakan hal penting untuk pemenunjang penyelenggara pendidikan nonformal. Taman bacaan masyarakat yang diselenggarakan oleh masyarakat dan untuk masyarakat bertujuan untuk memberi kemudahan akses kepada warga masyarakat memperoleh bahan bacaan dan menyelenggarakan pendidikan nonformal. Peranan penting Taman Bacaan Masyarakat sebagai penyelenggara pendidikan nonformal dan mengetahui penunjang dan kendala Taman Bacaan Masyarakat sebagai penyelenggaraan pendidikan nonformal.

Program pengembangan budaya baca yang dilaksanakan di Taman Bacaan Masyarakat selain memberi kemudahan mendapatkan bahan bacaan yang mendorong masyarakat gemar membaca seperti menentukan bahan bacaan yang relevan, berguna dan dibutuhkan masyarakat di sekitar Taman Bacaan Masyarakat (TBM), tujuannya untuk memperluas pengetahuan dan keterampilan demi peningkatan wawasan masyarakat. Penyelenggaraan Taman Bacaan Masyarakat ini merupakan suatu sumbangan yang sangat besar bagi masyarakat. Dimana minat baca masyarakat belum ada pada diri masyarakat, namun setelah hadirnya Taman Bacaan Masyarakat akan tumbuhlah minat baca masyarakat dan bahkan membaca menjadi suatu kebutuhan bagi masyarakat.
Seperti halnya Taman Bacaan Masyarakat CellPower Indonesia yang telah berdiri sejak tahun 2010 merupakan salah satu Taman Bacaan Masyarakat yang berada di kota Medan. Setelah melakukan observasi di Taman Bacaan Masyarakat Taman Bacaan Masyarakat CellPower Indonesia khususnya tumbuhnya minat membaca masyarakat semakin meningkat dimana pengunjung Taman Bacaan Masyarakat CellPower Indonesia pada tahun 2012 adalah 3600 orang, kemudian tahun 2013 adalah sebanyak 4800 orang, tahun 2014 adalah sebanyak 7000 orang, sementara pengunjung Taman Bacaan Masyarakat CellPower Indonesia pada tahun 2015 sampai dengan bulan maret adalah 2400 orang.

Namun dalam hal ini, masih banyak masyarakat yang belum pernah mengunjungi TBM bahkan mengartikan arti dari TBM sekalipun tidak tahu, meskipun lokasi ataupun tempat TBM itu sendiri berdekatan dengan tempat tinggalnya sendiri. Keberadaan TBM dilingkungan tempat tinggalnya bagi sebagian masyarakat beranggapan bahwa TBM adalah tempat kursus, les dan lain sebagainya. Anggapan masyarakat yang seperti hal ini, diperoleh dari hasil pantauan dan penglihatannya sendiri tanpa adanya keingintahuan yang lebih mendalam. Kenyataan seperti ini bukan hanya sekarang ini saja terjadi namun sudah sejak dulu setelah TBM di adakan untuk masyarakat. Pemberian informasi kepada masyarakat merupakan suatu hal sangat perlu dilakukan oleh pihak pengelola. Dengan adanya informasi yang disampaikan kepada masyarakat, akan berdampak positif terhadap kemajuan dan danya tarik masyarakat.

$$
\text { Pengunjung Taman Bacaan }
$$

Masyarakat CellPower Indonesia terdiri dari Anak PAUD (0-5 tahun), Anak-anak (6-12 tahun), Remaja (13-17 tahun), Dewasa (1859 Tahun), dan Lansia (60 tahun keatas ) dengan berbagai macam kebutuhan buku yang diinginkan oleh pengunjung. Dalam keseharian, pengunjung yang lebih banyak datang berkunjung lebih banyak di dominasi oleh anak-anak sekolah yang hendak 
mengerjakan tugas sekolahnya, sehingga disaat tugas sekolahnya tidak ada maka pengunjung TBM akan terlihat berkurang. Dengan keadaan yang seperti ini masyarakat yang berkunjung ke Taman Bacaan Masyarakat CellPower Indonesia membaca bukan berdasarkan minat ataupun keinginan untuk membaca, tetapi hanya untuk memperoleh apa yang dia cari seperti halnya anak sekolah yang mengunjungi Taman Bacaan Masyarakat CellPower Indonesia hanya untuk mengerjakan tugas sekolahnya semata.

\section{Taman Bacaan Masyarakat}

CellPower Indonesia ini buka setiap hari, mulai dari hari senin $\mathrm{s} / \mathrm{d}$ hari sabtu, pukul 09.00 Wib sampai dengan pukul 17.00 Wib. Selain sebagai suatu bentuk layanan bacaan masyarakat Taman Bacaan Masyarakat CellPower Indonesia juga menyediakan layanan internet sebagai perangkat tambahan, apabila pengunjung tidak menemukan ataupun ingin memperoleh bacaan yang lain. Taman Bacaan Masyarakat CellPower Indonesia juga digunakan dan mengadakan berbagai bentuk kegiatan pendidikan baik formal maupun pendidikan non formal dan gerakan literasi, seperti contohnya kegiatan pelatihan jurnalistik yang dilakukan minimal 1 kali dalam setahun, kegiatan mengumpulkan buku untuk menambah dan memperbaharui persediaan buku, kemitraan dengan sponsor ataupun melalukan kerjasama dengan toko-toko buku dan TBM yang lain, mencari sumbangan buku, melakukan bazar buku serta kegiatankegiatan lainnya.

Dengan berbagai faktor yang mempengaruhi minat baca masyarakat yang rendah peneliti tertarik untuk mengamati, meneliti serta mencermati bagaimanakah Taman Bacaan Masyarakat CellPower Indonesia dalam membantu mempercepat dalam peningkatkan minat baca pada masyarakat serta upaya yang dilakukan dalam meningkatkan minat baca tersebut dan memasyarakatkan layanan publik berupa Taman Bacaan Masyarakat CellPower Indonesia yang bertujuan menjadikan masyarakat yang gemar membaca Sehingga peneliti tertarik untuk mengkaji Upaya Pengelola Dalam Peningkatan Minat Baca Masyarakat Di Taman Bacaan Masyarakat Cellpower Indonesia Kota Medan.

\section{METODE PENELITIAN}

Untuk melihat, mengetahui serta mendeskripsikan keadaan yang sebenarnya secara rinci dan aktual dengan melihat masalah dan tujuan penelitian seperti yang telah disampaikan sebelumnya, maka metode penelitian yang digunakan dalam penelitian ini mengarah pada penggunaan metode penelitian kualitatif. Penelitian ini tidak menggunakan populasi dan sampel tetapi menggunakan subjek penelitian yaitu pengelola TBM yang berjumlah 4 orang yaitu: 1 orang pengelola, 1 orang Staf ( yang merangkap sebagai tutor kursus ) serta 2 orang pengunjung TBM Cellpower Indonesia. Jadi subjek penelitian ini berjumlah 4 orang yang merupakan sumber keterangan yang penting.

Pengumpulan data dilakukan dengan cara dokumentasi dan wawancara yang dilakukan secara mendalam (in depth interview) dengan informan yaitu pengelola 1 orang, tutor 1 orang, dan 2 orang pengunjung dengan jumlah 4 orang yang merupakan sumber keterangan yang penting.

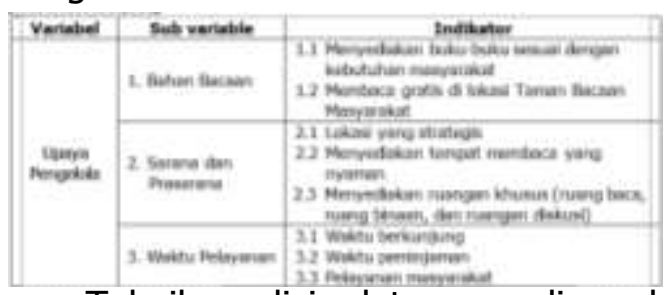

Teknik analisis data yang digunakan dalam penelitian ini adalah teknik analisis deskriptif kualitatif dengan mengorganisasikan data, memilihnya menjadi satuan yang dapat dikelola, mencari dan menemukan pola, menentukan apa yang penting dan apa yang dipelajari dan memutuskan apa yang dapat diceritakan kepada orang lain. Dalam penelitian ini analisis data dilakukan dengan tiga langkah reduksi data, penyajian data, penarikan kesimpulan dan verifikasi. 


\section{HASIL DAN PEMBAHASAN}

Taman Bacaan Masyarakat (TBM) merupakan sebuah lembaga yang menyediakan bahan bacaan yang dibutuhkan oleh masyarakat sebagai tempat penyelenggaraan pembinaan kemampuan membaca dan belajar. Selain itu, TBM juga merupakan tempat yang digunakan sebagai tempat untuk mendapatkan informasi bagi masyarakat, khususnya yang bersumber dari bahan pustaka. Bahan pustaka itu sendiri merupakan semua jenis bacaan dalam berbagai bentuk media.

Taman Bacaan Masyarakat (TBM) CellPower Indonesia berdiri dan mendapat ijin operasional dari Dinas Pendidikan Kota Medan berdasarkan SK Kepala Dinas Pendidikan Kota Medan no. 420/5167.PNFI/2010 tertanggal 13 April 2010 tentang Penetapan dan Pengesahan Pendirian Lembaga Taman Bacaan Masyarakat (TBM) CellPower Indonesia.

TBM Cellpower Indonesia beralamat di Jl. Adi Sucipto No. 5-6 Kecamatan Medan Polonia. TBM CellPower Indonesia di kelola oleh Bapak Andreas Peranginangin M.Si. TBM CellPower Indonesia berada tepat di sebelah PKBM Merah Putih Yang merupakan Bagian dari TBM CellPower Indonesai yang dikelola Oleh Bapak Andreas Peranginangin. Dengan adanya PKBM Merah Putih tersebut pengunjung yang datang ke TBM CellPower Indonesia juga diramaikan oleh peserta didik PKBM.

Perencanaan program di lembaga taman bacaan didasari atas kesesuaian visi dan misi lembaga. Pelaksanaan program kegiatan taman bacaan masyarakat CellPower Indonesia merupakan penjabaran program kerja rencana lima tahun dalam repelita dan rencana program kerja tahunan. Agar berhasil tentunya visi, misi program kerja lima tahun dan tahunan harus dibuat jelas dan terukur sehingga lembaga bersama dengan seluruh sumber daya manusianya dapat melaksanakannya sesuai dengan waktu kegiatan dan sasaran yang ingin dicapai.

Upaya Pengelola Dalam Peningkatan Minat Baca Masyarakat
Upaya pengelola dalam meningkatkan minat baca masyarakat di TBM CellPower Indonesia adalah suatu langkah yang dilakukan pengelola dalam meningkatkan minat baca masyarakat melalui tindakan yaitu: penyediaan koleksi bacaan yang lengkap dan sesuai dengan kebutuhan pembaca, penyediaan tempat/ sarana dan prasarana membaca yang aman dan nyaman, menambah kegiatan/program tambahan untuk menambah daya tarik pengunjung untuk membaca, serta menambah waktu pelayanan. Dengan adanya upaya yang dilakukan oleh pengelola dalam meningkatkan minat baca masyarakat tersebut, akan dapat membuat pengunjung Taman Bacaan CellPower Indonesia semakin tertarik dan berminat untuk membaca serta mengikuti kegiatan ataupun program yang telah disusun oleh Taman Bacaan CellPower Indonesia itu sendiri.

\section{Pembahasan}

Berdasarkan hasil wawancara penulis dapat menyimpulkan bahwa pengelola Taman Bacaan CellPower Indonesia telah melakukan upaya dalam peningkatan minat minat baca masyarakat dengan baik. Upaya-upaya yang dilakukan oleh pengelola yaitu dengan menyediakan tempat, fasilitas serta bahan bacaan yang lengkap dan nyaman bagi pengunjung, melakukan perbaharuan bahan bacaan yang disediakan di TBM, mengupayakan pelayanan yang baik kepada masyarakat agar masyarakat semakin tertarik dan nyaman saat berkunjung, membangun kerjasama serta hubungan yang baik dengan pihak donator yang dapat membatu dalam penyumbangan bahan bacaan, kemudian dengan pihak pengelola TBM lain, dan juga masyarakat setempat, meninjau keluhan-keluhan dialami oleh pengunjung agar dapat di perbaiki ataupun di atasi untuk jangkau waktu kedepannya, memberikan motifasi-motifasi kepada pengunjung agar masyarakat lebih memahami betapa pentingnya manfaat membaca dalam kehidupan sehari-hari, mengadakan program-program atapun 
kegiatan-kegiatan yang diadakan di TBM, agar masyarakat tidak merasa bosan dengan kegiatan-kegiatan yang dilakukan di TBM. Memberikan penghargaan kepada masyarakat yang ikut berpartisipasi dalam kegitan yang diadakan di TBM, agar pengunjung atapun masyarakat merasa berharga di dalam setiap kegiatan yang diikutinya di TMB.

\section{SIMPULAN}

Berdasarkan penelitian yang telah dilakukan di TBM CellPower Indonesia, pengelola telah berupaya melaksanakan tugasnya dengan baik dan sesuai dengan tugas dan fungsinya dalam meningkatkan minat baca masyarakat. Dimana upaya yang dilakukan oleh pengelola yaitu dengan melakukan tindakan seperti, menyediakan buku-buku ataupun bahan bacaan yang lengkap bagi para pengunjung mulai dari bahan bacaan yang berbau pendidikan, pengetahuan umum, kesehatan, serta surat kabar. menyediakan tempat membaca/ ruang baca yang aman dan nyaman, menambah kegiatan/program tambahan untuk menambah daya tarik pengunjung untuk membaca berupa lomba baca buku, bazar, pentas seni musik, bulan berbagi buku, memberikan informasi kepada pengunjung ataupun masyarakat serta menambah waktu pelayanan.

Upaya yang dilakukan oleh pengelola sangat bermanfaat terhadap kemajuan dan kelancaran program yang telah direncanakan demi tercapainya tujuan yang ingin dicapai oleh TBM, dengan adanya perhatian dan upaya yang dilakukan oleh pengelola TBM diharapakan dapat lebih berkembang serta bermanfaat di kalangan masyarakat. Peran pengelola sangat penting dalam membangun kemitraan yang luas dengan masyarakat maupun dengan lembaga-lembaga TBM lainnya.

\section{DAFTAR PUSTAKA}

Hatimah, Sadri. 2008. Pembelajaran Berwawasan kemasyarakatan, Jakarta: Universitas Terbuka.

Kamus Besar Bahasa Indonesia. 2005. Arti Membaca.

Manullang. 2012. Manajemen Sumber Daya Manusia, Medan: Citapustaka

Moleong. 2003. Metode Penelitian Kualitatif. Bandung: Remaja Rosdakarya

Rahim F. 2008. Pengajaran Membaca di Sekolah Dasar, Jakarta: PT Bumi Aksara

Saddhono, Slamet. 2012. Meningkatkan keterampilan berbahasa Indonesia, Bandung: CV. Karya Putra Darwati.

Sugiyono. 2012. Metode Penelitian Pendidikan (Pendekatan Kuantitatif, Kualitatif, dan $R$ \& D). Bandung: Alfabeta.

Sugiyono. 2013. Metode Penelitian Pendidikan (Pendekatan Kuantitatif, Kualitatif, dan R\&D), Bandung: Alfabeta,CV.

Susanto A. 2013. Teori Belajar Dan Pembelajaran Di Sekolah Dasar, Jakarta: PT Bumi Aksara

Sudirman. 2012. Manajemen Pelatihan, Medan: Unimed Press

Wau Y. 2014. Profesi Kependidikan, Medan: Unimed Press 